\title{
盛土周辺地盤への变位抑制効果に着目した地盤改良について†
}

近藤 益央* 宮武 裕昭*

\section{A Soil Improving Method Capable of Controlling Peripheral Ground Displacement}

by

\section{Masuo $\mathrm{KONDOH} *$ and Hiroaki MIYATAKE *}

A deep mixing stabilization method is often adopted as soft ground measures. For the purpose of cost reduction, the economical method is suggested, such as the floating type or low improved rate type. If we build road embankment on the soft ground at a near the house, in danger of a house inclining because the ground sinks. Therefore we need the new soft ground improvement method for the subsidence and displacement depression technique of the peripheral ground.

In this report, we introduce the result of the centrifuge model test. Furthermore, we report measures effect of the road embankment on the soft ground. To obtain a satisfactory sideways flow preventive effect by effectively reinforcing the banking support ground by improving soil having a low improvement rate.

\section{Key words:}

Deep mixing method, Hybrid application, Cement column, Cement pile wall,

Displacement restraint

\section{1 緒言}

近年,軟弱地盤を対象とした地盤改良工法として深層混 合処理工法が盛んに用いられるようになり,コスト縮減を 目的として浮型や低改良率型の経済的な地盤改良工法が 提案されている.しかし,家屋等の周辺構造物が近接して いる場所での道路盛土構築事例も増えており,有明沿岸道 路をはじめとする多くの現場では,盛土沈下に伴う側方流 動や引き込み沈下を抑制するために,様々な制限值を設定 しており,周辺地盤への变形抑制効果が期待出来る工法が 求められる.このような場合,盛土直下全面を改良する工 法や,盛土法尻部を集中的に高改良率で改良する工法等が 採用されることが多い.これらの工法は,変形抑制効果が 高いがコス卜高になったり,コストはある程度低減できる が法尻部の側方変形が十分に抑えられなかったりなどの 課題があった.そこで外部杭,側部壁,内部杭といった改良 体を低改良率かつ機能的に配置し, 経済性と周辺地盤への 影響の抑制を両立した杭状・壁状配置併用型地盤改良工 法（以下，「コラムリンク工法」と呼ぶ）を民間 13 社と共 同開発した。

本報告では,遠心力載荷模型実験による本工法の効果を 紹介するとともに,国道 57 号熊本宇土道路で実施した本 工法の試験盛土区間における盛土沈下および周辺地盤に おける沈下および水平変位等に関する動態観測結果につ いて報告するものである.

\section{2 コラムリンクエ法の概要}

コラムリンク工法は,深層混合処理工法により造成した
杭状改良体と壁状改良体を機能的に配置したもの 1 ) で,Fig.1 に概念図を示す.壁状改良体を側部壁と呼び,側部 壁より盛土中心側の杭状改良体を内部杭, 側部壁から盛土 法尻側の杭状改良体を外部杭とそれぞれ呼んでいる.これ らの改良体の配置仕様を現場の条件や要求性能に合せて 設計することで,経済性と側方流動の抑止を両立させるこ とが可能である.例えば,法尻から $10 \mathrm{~m}$ 地点の鉛直変位が $2 \mathrm{~cm}$ という条件で従来工法である法尻全面改良工法と比
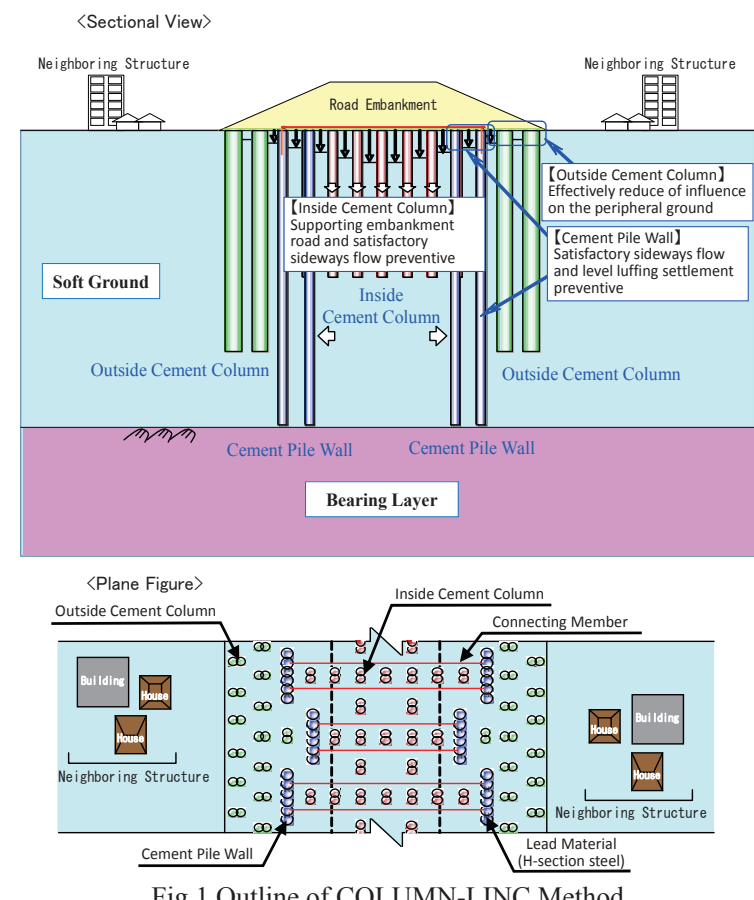

Fig.1 Outline of COLUMN-LINC Method.

$\dagger$ 原稿受理 平成29年 6月12日 Received June 12, 2017 (C2018 The Society of Materials Science, Japan

* (国研)土木研究所 地質・地盤研究グループ施工技術チーム

Geology and Geotechnical Engineering Research Group, Public Works Research Institute, Minamihara, Tsukuba 305-8516. 
較すると,コラムリンク工法は従来工法に対して直接工事 費で約 40\%縮減,工期では約 50\%短縮することが可能であ る.盛土周辺地盤に発生する変状を経済的に抑制すること が可能であることから,民家等に近接して施工が必要な区 間で,周辺地盤の変位・沈下制限が厳しい工区での地盤改 良工法として適している.側部壁,内部杭,外部杭は従来の 深層混合処理工法で用いられている $\Phi 1,000 \sim 1,300 \mathrm{~mm}$ の 2 軸型改良機を用いて構築し,特殊な施工機械を必要とし ないことも特徴である.

コラムリンク工法は側部壁,内部杭,外部杭の主要 3 部材 に,側部壁頭部を連結する芯材と繋ぎ材,地表面に設置す る敷網材で構成される.

各部材は,沈下や側方流動を抑制できるそれぞれの機能 を有しており, 沈下や変位の制限值などの要求性能を考慮 して,機能的に配置する。

以下に本工法の構成部材とその機能を示す.

(1)側部壁

盛土法肩下に配する壁状改良柱体.盛土荷重を深部に伝 達すると伴に, 壁内外の地盤の側方流動を遮断し, 盛土の 沈下・側方流動の抑制に寄与寸る.また,地下水流動阻害防 止の観点から,盛土奥行方向に連続とせず,互い違いに配 置することを基本とする

(2)内部杭

盛土天端下に配する改良柱体.盛土荷重を地盤深部に伝 達し,主に盛土の沈下抑制に寄与寸る.

(3)外部杭

盛土法面下に配する杭状柱体.盛土法面下の沈下を抑制 し,周辺地盤の影響を緩和する.

(4)繋ぎ材と芯材

繋ぎ材で側部壁頭部を繋ぐことによって，盛土施工時 に懸念される偏心荷重による側部壁頭部の傾斜への対策 として設置し,盛土施工時に発生する周辺地盤への变状抑 止することができる.側部壁頭部に挿入した芯材 $(\mathrm{H}$ 鋼 $)$ を繋ぎ材 ( $\mathrm{PC}$ 鋼より線) により連結したもの.

(5)表層部材（敷網材および浅層固化盤）

敷網材（ジオテキスタイル）は,側部壁・内部杭・外部 杭の天端部に設置する.盛土施工初期における改良体移動

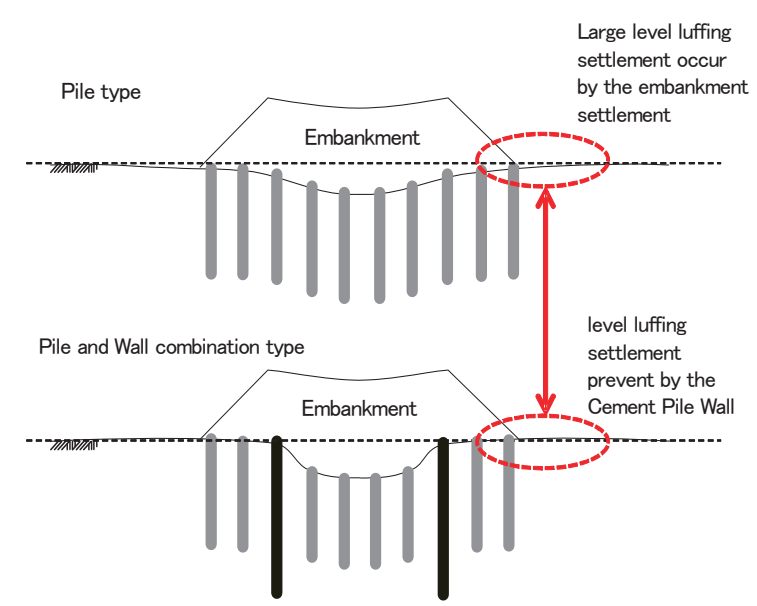

Fig.2 Outline of prevent displacement of peripheral ground.
を抑止する目的で設置する部材である.

コラムリンク工法の特徵は,側部壁の「着底」,「拘束」, 「遮断」効果である.側部壁の「着底」,「拘束」,「遮断」 の 3 つの効果は,以下のように特徴づけられる.

(1)着底効果による分担荷重の低減

着底効果は,側部壁を軟弱地盤下の支持地盤に着底させ て盛土荷重支持の強化を図ったものである.もっとも盛土 高が大きくなる盛土のり肩間の範囲で,両側の側部壁天端 を基点としたアーチ作用により,側部壁への盛土荷重の集 中が発生するため, 盛土中央部軟弱地盤への作用荷重が軽 減して,その領域の沈下を低減できる.

(2)拘束効果による盛土沈下の低減

拘束効果は,盛土法肩部下で道路縦断方向に沿って設置 した側部壁によって発揮されるものである.盛土荷重によ る軟弱地盤の沈下に伴って生じる側方変位成分を,内部杭 より深い位置の側部壁により拘束することで,一次元圧密 と同様な条件で側部拘束が効いた状態にできることから， これにより中央部の沈下を低減できる.

(3)遮断効果による周辺地盤の沈下と変位抑制

遮断効果は,盛土中央部での沈下や側方変形がのり尻部 や周辺地盤に影響が及ばないように, 側部壁で縁切り遮断 するものである.Fig.2 に示すように, 盛土中央部の沈下影 響を側部壁によって取り除くことができるため,周辺地盤 の沈下と水平変位の許容值に対して,外部杭の設計仕様を 従来の杭状改良工法に比べて軽微なものとできる.

\section{3 コラムリンクエ法の遠心力載荷模型実験}

試験施工や解析を実施する前段階として,コラムリンク 工法の力学挙動を示し,どのようなモデル化が望ましいか を把握する必要がある.そこで, 層厚の深い粘性土地盤に 対する遠心模型実験を実施し, 周辺地盤への変形抑制に与 える影響の把握と, 通常の低改良率工法との比較による経 済性の検討, 地盤挙動モデルの確認, コラムリンク工法の 構造の検討を行った.

3.1 実験の概要

実験模型の概要図を Fig.3 に,実験のケースを Table 1 に 示す.有明粘土を想定した地盤（地表面のせん断強度 $\mathrm{Cu}$ : $9.6 \mathrm{kPa}$ ）に対し,過剩間隙水圧の消散を確認後,サンドホッ パーにて $7 \mathrm{~m}$ 相当の盛土荷重を急速載荷し,実大換算で約 1 年間,荷重を維持し, 周辺地盤の水平変位量, 沈下量の評価 を行った.実験ケースは無対策 (Case 1), 低改良率 (Case2 : 軟弱地盤層厚 $19.8 \mathrm{~m}$ に対して杭長 $15 \mathrm{~m}$ の浮式で,改良率 $10.5 \%$ ）,内部杭の長さを変化させたコラムリンク工法 （Cas3～5）で比較する形で実施した.

3.2 実験結果

3.2 .1 側部壁への荷重集中の様子 コラムリンク工法の 実験後の沈下状況を Fig.4 に示す.側部壁の内側にて弧状 に沈下が発生する様子を確認できた.これは支持層に着底 している側部壁に盛土荷重が集中し,改良杭が着底してい ない盛土中央部直下では未改良地盤に圧密沈下が発生し ていることを示している.予備的に実施した解析では,側 

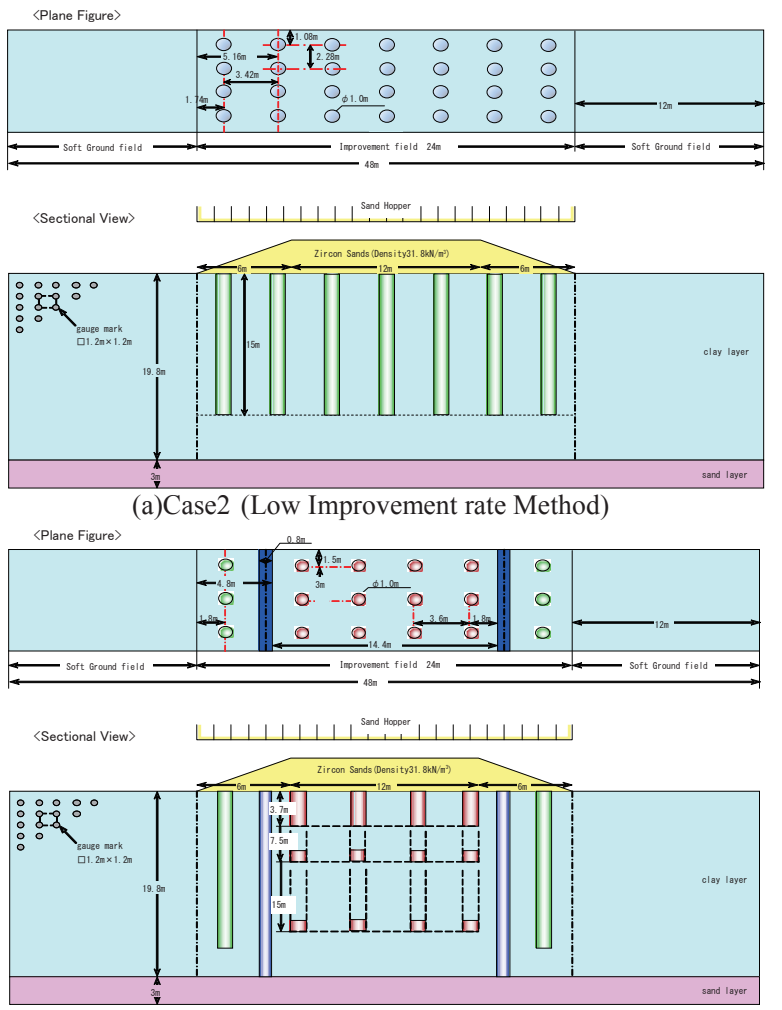

(b)Case3 $\sim 5$ (COLUMN-LINC method)

Fig.3 Outline of Centrifuge Model Test.
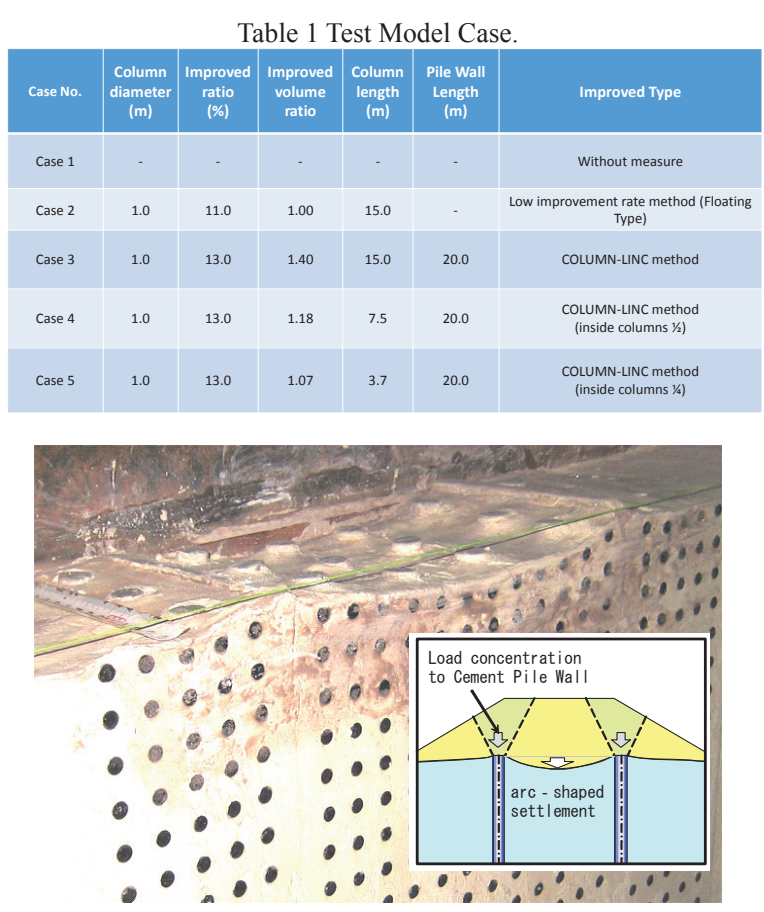

Fig.4 Status of Settlement (Case3).

部壁の位置を変化させたところ,側部壁の位置が法局から 遠くなると,盛土の沈下量も大きくなる傾向があった.ま た,側部壁の位置が法肩から離れ法尻側に近づくと,側部 壁を法尻側に押寸側方流動力も大きくなるため,盛土天端 幅の広い盛土では,繋ぎ材による変形抑制効果の重要性が 增すと考えられる。

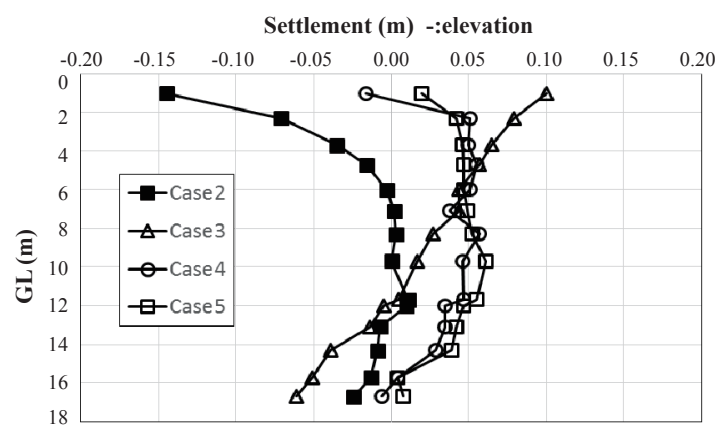

Fig.5 Settlement at foot of slope.

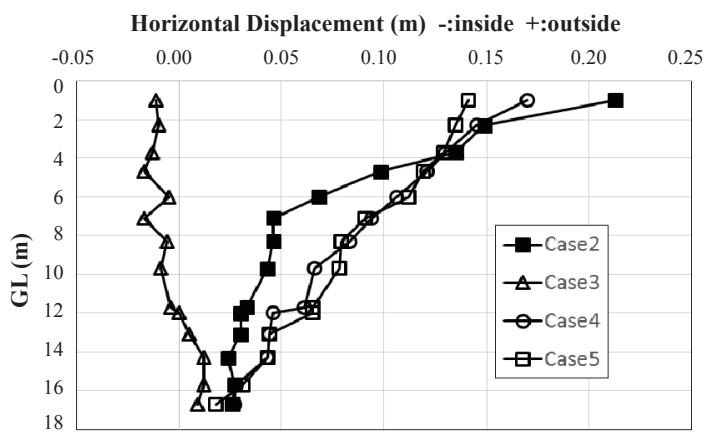

Fig.6 Horizontal Displacement at foot of slope.

3.2 .2 標点の移動量による各ケースの評価 軟弱地盤に 設置した標点（縱横 $1.4 \mathrm{~m}$ pitch）に対する動画解析を行い, 各ケースの結果を比較した.各ケースの盛土法尻部におけ る沈下量並びに水平変位量を Fig.5,Fig.6 に示寸. (Case1 はすべり破壊により省略）これより,内部杭を短くした Case4,5 においても,Case2 と比較して,水平変位量では同等, 沈下量ではそれ以上の性能を有することが分かった。

\section{4 熊本宇土道路での試験施工}

熊本宇土道路の建設予定地は,軟弱な粘性土が厚く堆積 している区間があり,人家が盛土に近接区間では,盛土建 設によって周辺地艋に発生する変状を抑制する必要があ る.このような区間での工法の候補として,コラムリンク 工法の試験施工 ${ }^{2}$ )が行なわれ,盛士の施工開始(2010 年 3 月 19 日)から動態観測 3)が実施されたので,ここで紹介寸る. 4.1 試験施工

Fig.7 および Fig.9 に示すように基礎地盤までの全体層 厚が 36.2mあり,GL-4.5m〜 GL-11.2m に砂層(As2)を挟んで いるが,それ以外の層は軟弱な粘性土地盤で,道路盛土に よる圧密沈下による側方流動により, 周辺地盤に大きな変 状が発生する危険があった.試験施工区間の周辺には田畑 があるため,側部壁によって地下水の流動を阻害する危険 を避けるため,側部壁を縦断方向に連続的に配置しないで 千鳥に配置した.そのため,側部壁が法肩から法尻側に離 れた位置に配置し,繫ぎ材として $\phi 15.2 \mathrm{~mm}$ の $\mathrm{PC}$ 鋼より線 を用いた.また周辺地盤の変状抑止効果を高めるために, 外部杭は着底とした. Fig.8に改良体の平面配置を示寸.ま た, Fig.9 に盛土構築後の写真を示す. 


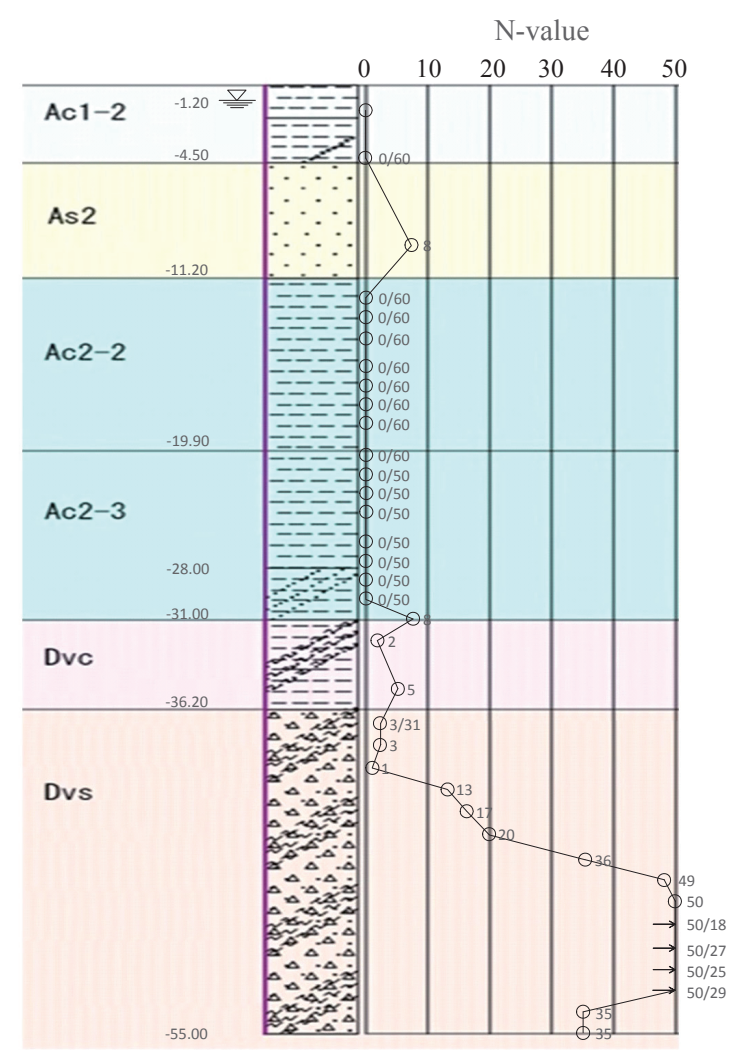

Fig.7 Soil profile.

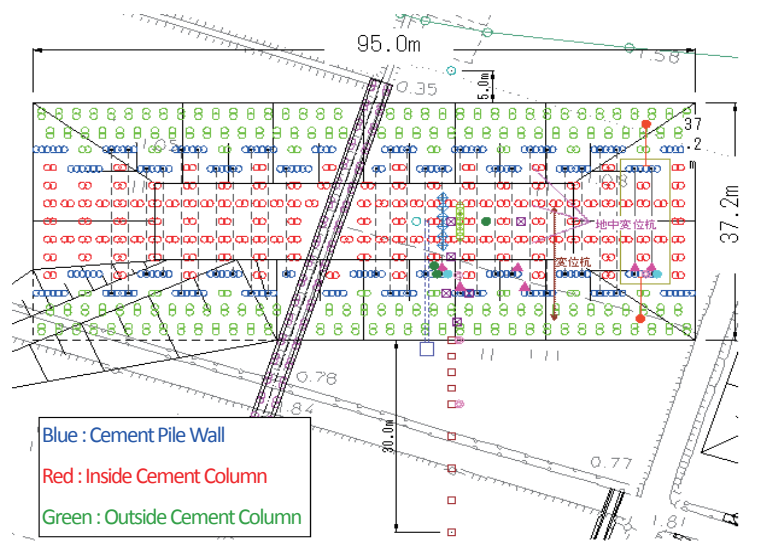

Fig.8 Arrangement of measuring apparatus.

Fig.12 に施工が完了した時点での改良杭の縦断方向と 横断方向の配置を示寸.頭部が黄色くなっている部材 $(\bigcirc$ 印)は,繋ぎ材を固定するために側部壁に挿入されている 芯材 $(\mathrm{H}$ 鋼)である.

\section{2 動態観測}

動態観測は,沈下板・層別沈下計・地中変位計・鉛直土 圧計・改良体ひずみ計・地下水位計・間隙水圧計・盛土 下伸縮計・繋ぎ材張力計の 9 項目を対象にして実施し た.Fig.10,11 に示寸計測器の配置で,盛土の施工開始(2010 年 3 月 19 日)から盛土完成後 40 ケ月 (2014 年 3 月 6 日) ま での動態観測を実施した。

\section{(1) 沈下量}

コラムリンク工法の盛土中央部における地表面沈下の 経時変化を Fig.13 に,周辺地盤における盛土完成直後と盛 土完成後 40 ケ月の沈下量を Fig. 12 に示す.盛土完了直後で の沈下量 $\mathrm{S}$ は,中央部で $\mathrm{S}=12.4 \mathrm{~cm}$,のり尻直下で $\mathrm{S}=2.6 \mathrm{~cm}$,

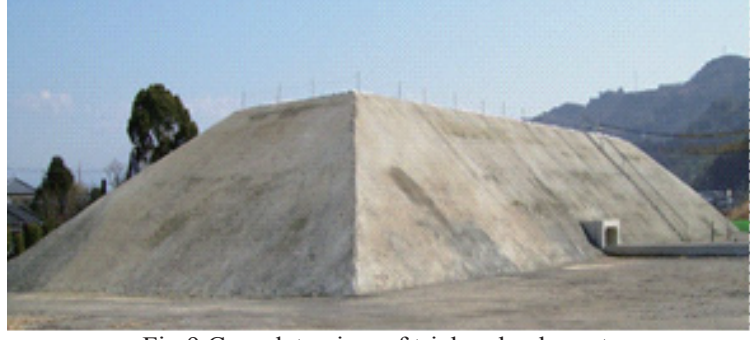

Fig.9 Complete view of trial embankment.

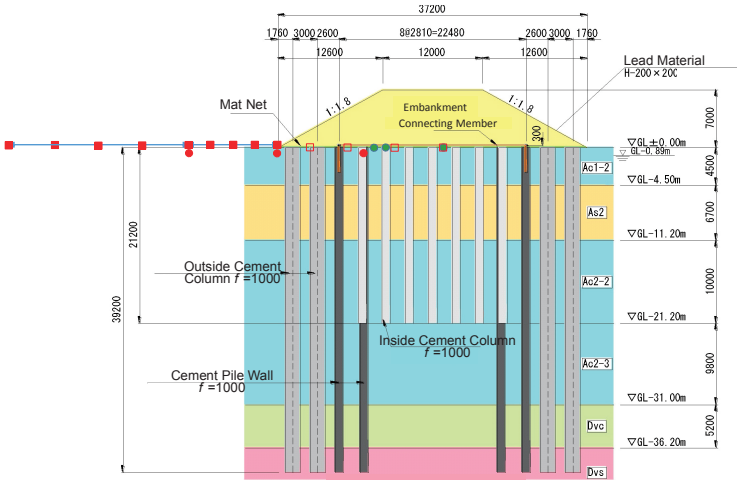

Fig.10 Sectional view of trial construction.

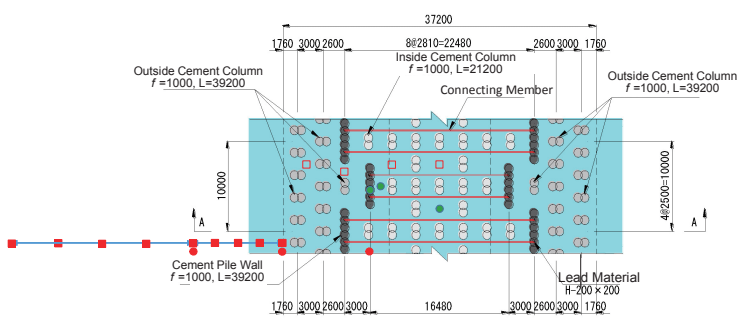

Fig.11 Plane figure of trial construction.

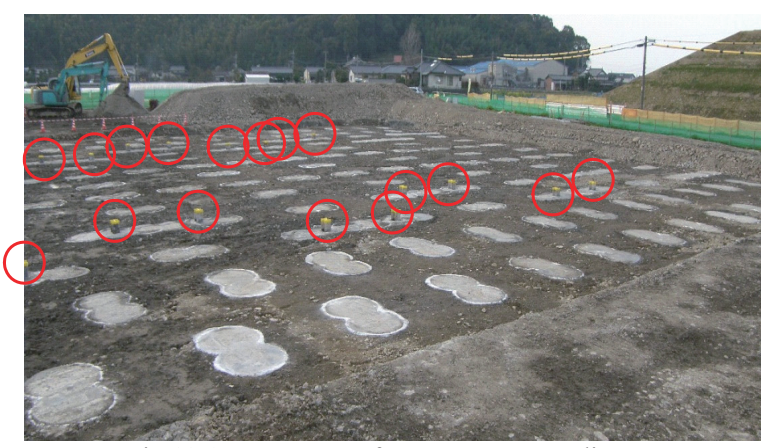

Fig.12 Arrangement of Improvement Bodies

のり尻から $10 \mathrm{~m}$ 距離で $\mathrm{S}=2.6 \mathrm{~cm}$, のり尻から $30 \mathrm{~m}$ 距離で $\mathrm{S}$ $=1.6 \mathrm{~cm}$ であった.盛土完成後 40 ケ月の沈下量 $\mathrm{S}$ は, 中央部 で $\mathrm{S}=21.8 \mathrm{~cm}$,のり尻直下で $\mathrm{S}=3.8 \mathrm{~cm}$,のり尻から $10 \mathrm{~m}$ 距離 で $\mathrm{S}=5.0 \mathrm{~cm}, 30 \mathrm{~m}$ 距離で $\mathrm{S}=2.9 \mathrm{~cm}$ であった.Table 2 に示し た当該区間の変位制限值は,盛土中央部での残留沈下量が $30.0 \mathrm{~cm}$ 以内,住宅近接部ではのり尻から $10 \mathrm{~m}$ 距離での施工 開始後からの沈下量が $2.0 \mathrm{~cm}$ 以内となっている.盛土中央 部での残留沈下量は $9.4 \mathrm{~cm}$ と変位制限值を満足している が,のり尻から $10 \mathrm{~m}$ 距離での施工開始後からの沈下量は制 限值 $2.0 \mathrm{~cm}$ に対して盛土完成後 40 ケ月では $5.0 \mathrm{~cm}$ と制限 值を大きく上回ってしまった.これは,盛土のり面下に構 築した外部杭区間で生じた沈下により,盛土周辺部におい ても引き込み沈下が発生しているものと考えられる.この 
Table 2 limiting value of trial construction.

\begin{tabular}{|c|c|c|c|c|c|c|}
\hline & \multirow{2}{*}{ Road } & \multicolumn{5}{|c|}{ Peripheral Ground } \\
\hline & & \multicolumn{3}{|c|}{ Building } & $\begin{array}{l}\text { Irrigation } \\
\text { Channel }\end{array}$ & Farm \\
\hline $\begin{array}{l}\text { Evaluation } \\
\text { Item }\end{array}$ & $\begin{array}{l}\text { Residual } \\
\text { Settlement }\end{array}$ & $\begin{array}{c}\text { Total } \\
\text { Settlement }\end{array}$ & $\begin{array}{l}\text { Relative } \\
\text { Settlement }\end{array}$ & $\begin{array}{l}\text { Distortion } \\
\text { Angle }\end{array}$ & $\begin{array}{c}\text { Total } \\
\text { Settlement }\end{array}$ & $\begin{array}{c}\text { Total } \\
\text { Settlement }\end{array}$ \\
\hline $\begin{array}{l}\text { Evaluation } \\
\text { Period }\end{array}$ & $\begin{array}{l}\text { After the } \\
\text { Service }\end{array}$ & \multicolumn{5}{|c|}{ After the Starting of Construction } \\
\hline $\begin{array}{l}\text { Evaluation } \\
\text { Position }\end{array}$ & $\begin{array}{l}\text { Embankment } \\
\text { Field }\end{array}$ & \multicolumn{3}{|c|}{$10 \mathrm{~m}$ form Foot of Slope } & \multicolumn{2}{|c|}{$4 \mathrm{~m}$ form Foot of Slope } \\
\hline $\begin{array}{c}\text { Limit of } \\
\text { Settlement }\end{array}$ & $\leqq 300 \mathrm{~mm}$ & $\leqq 20 \mathrm{~mm}$ & $\leqq 10 \mathrm{~mm}$ & $\leqq 0.3 \times 10^{-3}$ & $\leqq 100 \mathrm{~mm}$ & $\leqq 100 \mathrm{~mm}$ \\
\hline $\begin{array}{c}\text { Limit of } \\
\text { Horizontal } \\
\text { Displacement }\end{array}$ & $\leqq 100 \mathrm{~mm}$ & $\leqq 20 \mathrm{~mm}$ & - & - & $\leqq 100 \mathrm{~mm}$ & $\leqq 100 \mathrm{~mm}$ \\
\hline
\end{tabular}
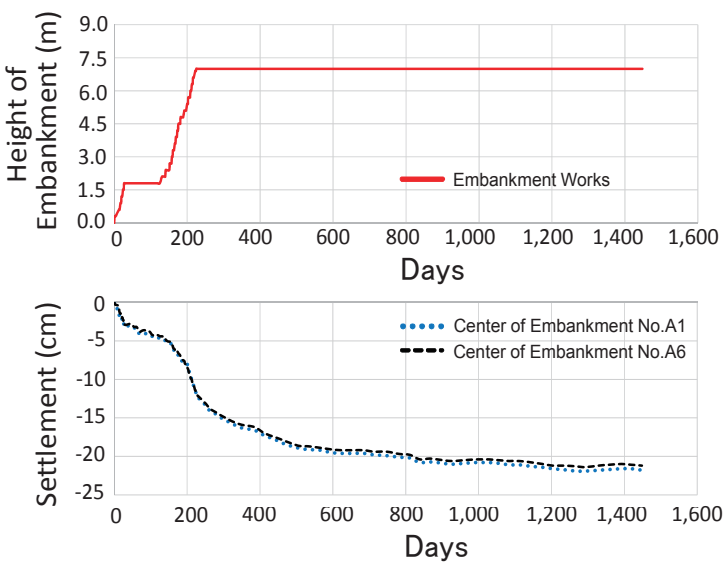

Fig.13 Time history of Settlement at center of embankment.

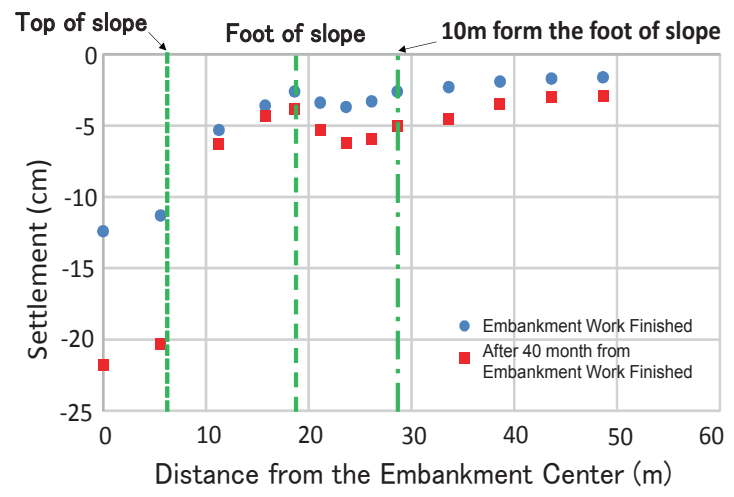

Fig.14 Settlement of ground surface.

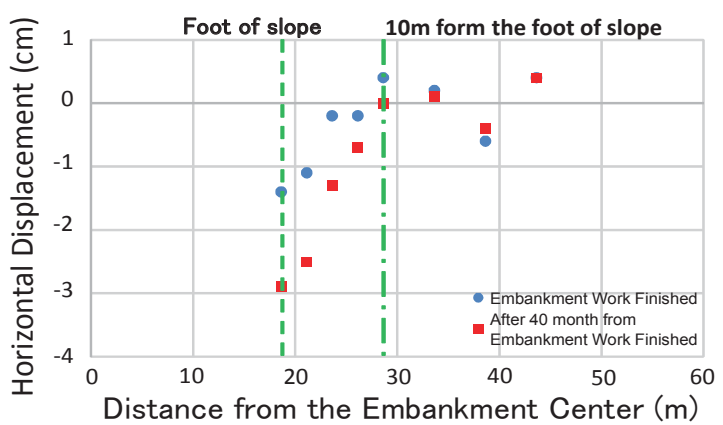

Fig.15 Horizontal displacement of peripheral ground.

ため,外部杭の改良率を高くし,のり面直下での沈下量を 更に抑制させる必要があることがわかった。

(2) 水平変位量

周辺地盤における盛土完成直後と盛土完成後 40 ケ月の 水平変位量を Fig. 15 に示す.盛土完了直後での水平変位は, のり尻部 $-1.4 \mathrm{~cm}$,のり尻から $10 \mathrm{~m}$ 距離で $0.4 \mathrm{~cm}$ であった.盛 土完成後 40 ケ月の水平変位は,のり尻部 $-2.9 \mathrm{~cm}, の り$ 尻か ら $10 \mathrm{~m}$ 距離で $0.0 \mathrm{~cm}$ であった.ここで,水平変位のマイナス

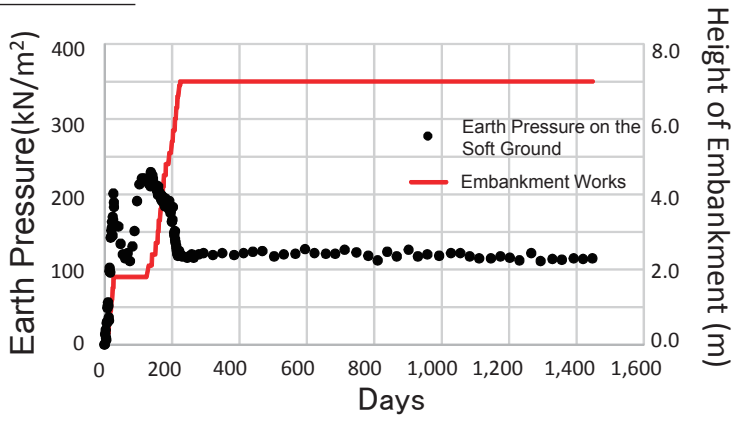

Fig.16 Earth Pressure on the Soft Ground.

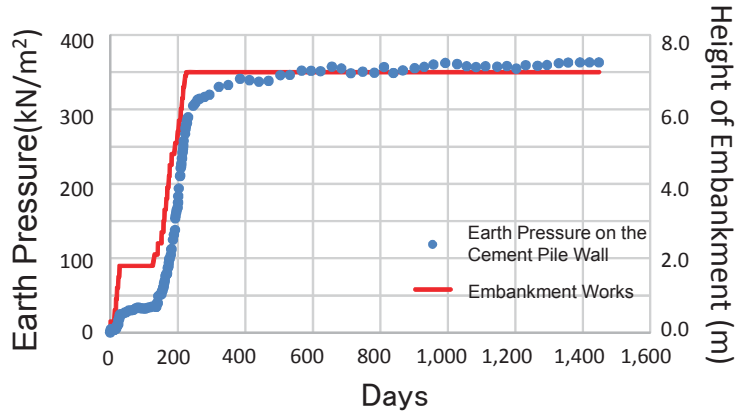

Fig.17 Earth Pressure on the Cement Pile Wall.

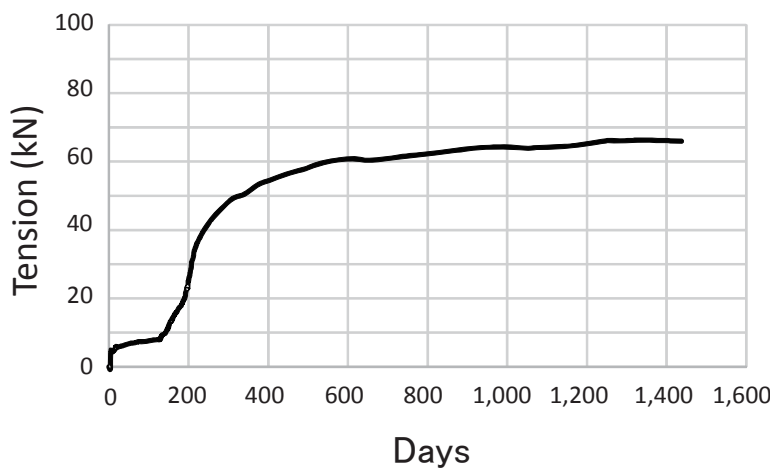

Fig.18 Tension of Connecting Member.

は盛土中心部方向への変位を示している.すなわち,(1)の 沈下量でも記述したとおり,盛土のり面直下での沈下にと もない,盛土周辺部でも引き込夕沈下にともなった水平変 位が発生していることがわかる.当該区閒におけるのり尻 から $10 \mathrm{~m}$ 距離での許容水平変位は許容沈下量と同様に $2.0 \mathrm{~cm}$ 以内となっており,この制限值を満足することがで きた.これは,側部壁の効果により盛土沈下による側方流 動が抑制できていることがわかる.

(3) 側部壁および未改良地盤に作用する土圧

側部壁天端の鉛直土圧時刻歴を Fig.16 に示す.盛土高さ $1.8 \mathrm{~m}$ までは土圧の上昇は緩やかであったが, $1.8 \mathrm{~m}$ より高 くなると側部壁へ盛土荷重が集中寸る傾向が表れる.これ に対して,Fig.17 に示した側部壁近傍の未改良地盤の鉛直 土圧時刻歴では開始初期に鉛直土圧が増加するが,その後 土圧は減少していることがわかる.これは,盛土構築初期 の段階では未改良地盤の圧密沈下により盛土荷重が集中 的に作用したものと考えられる.盛土直下には 2 方向にジ オテキスタイルを敷設しており,未改良地盤の圧密沈下に よってジオテキスタイルに緊張力が作用し, 増加した盛土 荷重がジオテキスタイルを介して側部壁等の改良体に集 
中的に作用し,未改良地盤には大きな盛土荷重が作用して いないことが確認できた。

\section{(4) 繋ぎ材}

側部壁に設置した繋ぎ材は，盛土構築時の偏荷重に よって生じる側部壁頭部開き方向の水平変位をより強く 拘束するために設置する仮設材である.繋ぎ材は側部壁打 設後すぐに長さ $3 \mathrm{~m}$ の $\mathrm{H}$ 鋼を挿入し,ジオテキスタイルお よび敷砂を敷設した後に側部壁に挿入した向かい合う H 鋼頭部を PC より線で繋いだ.繋ぎ材には初期張力は与え ず,待ち受け状態として設置した.Fig.18に示したとおり,繋 ぎ材に作用した張力は $60 \mathrm{kN}$ 程度であり,使用したより線 の降伏荷重が $183 \mathrm{kN}$ であったことから十分な安全率を有 していることがわかる.繋ぎ材に作用する張力は,側部壁 の設置位置や壁間隔によって異なり,今回の試験盛土では 側部壁設置位置が法肩より外側にあったことから,やや大 きい目の張力が作用したと考えられる。

\section{5 結言}

外部杭,側部壁,内部杭といった改良体を低改良率かつ 機能的に配置した杭状・壁状配置併用型地盤改良工法 (コ ラムリンク工法）の遠心力載荷模型実験および試験盛土 による動態観測結果から得られた知見をまとめると下記 のとおりである.

(1)側部壁には,側方流動の遮断効果と盛土荷重を分担する 役割があり,遮断効果により側部壁から盛土中心側にあ る内部杭以深の粘性土層で発生する沈下量を抑制して いる.また盛土荷重を分担する割合が高く,その荷重を 支持層に伝えているため,内部杭・外部杭以深の粘性土 層に作用する荷重が小さくなることによって,圧密沈下 量を抑制する効果を発揮することがわかった。

(2)コラムリンク工法の試験施工とそれに関連する実験の 検討により,側部壁の遮断効果により側部壁外側での沈 下や水平変位を抑制できることなど,周辺地盤への影響 抑制効果を確認寸るとともに,具体的な施工方法と施工 時の留意点等を確認することができた.

(3)ジオテキスタイルを敷設することにより,盛土荷重を改 良体に鉛直応力として伝達できており,未改良地盤への 荷重分担が軽減できていることにより,沈下量が抑制で きていることが確認できた.

(4)内部杭は外部杭に比べて盛土の沈下抑制効果が高く,外 部杭には周辺地盤の変状を抑制する効果が大きいこと がわかった.しかし,外部杭領域で発生する沈下量は周 辺地盤への影響が大きく,周辺地盤の引き込み沈下を誘 導していることがわかった.このため,外部杭の地盤改 良率を高くし,沈下量を抑制することが周辺地盤への影 響を小さくするために重要であることがわかった。

今後は更に試験施工等の実施例を増やし,周辺地盤への 影響を軽減する方法を開発したいと考えている.また,外 部杭,側部壁,内部杭といった杭状・壁状配置併用型地盤改 良工法であることから,盛土沈下量や周辺地盤への影響を 評価するためには解析的検討が必要となる.そこで 3 次元
的な改良形状の効果を設計で反映させるために,3 次元 FEM 解析を用いた検討 ${ }^{8)}$ も実施している.今後は, 動態観測 結果を踏まえて解析結果の精度向上を図ると共に,より簡 便な設計・解析手法の確立を目指寸ことが必要と考える.

なお,試験施工が行なわれた熊本県宇土市笹原は, 平成 28 年 4 月 16 日に発生した熊本地震 (本震 : M7.3) の震央 から約 $15 \mathrm{~km}$ に位置していたが,地震から約 1 个月後の 5 月 11 日に現地調査を行ったところ,試験盛土には顕著な 変状は確認できなかった。

\section{参 考 文 献}

1) S. Tsutsumi, H. Kohashi and T. Sawamatsu, "An experimental investigation of the Hybrid Application of Deep Mixing Columns Combined with Walls by the Centrifuge Model Test", Proceedings of the Japan Society of Civil Engineers Annual Meeting, CD-ROM, Vol. 65, No. 3, pp.1007-1008 (2010).

2) N. Shinkawa, S. Tsutsumi, M. Kawahara and H. Kawasaki, "An trial construction of the Column Link Method for lateral flow measures at the Kumamoto-Uto roadway", Proceedings of the Japan Society of Civil Engineers Annual Meeting, CD-ROM, Vol. 65, No. 3, pp.1005-1006 (2010).

3) S. Kawasaki, T. Higuchi, S. Tsutsumi and N. Shinkawa, "A field observation of the improved ground which applied Column Link Method at the Kumamoto-Uto roadway”, Proceedings of the Japan Society of Civil Engineers Annual Meeting, CD-ROM, Vol. 66, No. 3, pp. 51-52 (2011).

4) H. Matsui, H. Ishii, S. Miyagawa, K. Kamimura and K.Ryoukai, "A suggestion of the simple settlement calculation technique of the improved ground which applied Column Link Method", Proceedings of the Japan Society of Civil Engineers Annual Meeting, CD-ROM, Vol. 68, No. 3, pp. 143-144 (2013).

5) H. Matsui, H. Ishii and K. Horikoshi, "Hybrid Appli-cation of Deep Mixing Columns Combined with Walls as a Soft Ground Improvement Method Under Embankment", Proceedings of the 18th International Conference on Soil Mechanics and Geotechnical Engineering, Vol. 18, pp.2545-2548 (2013).

6) S. Tsutsumi, T. Sawamatsu, Y. Iso and T. Oshita, "Centrifuge Model experiment of new improvement type in deep mixing method with steel tied by cable for lateral flow", Proceedings of International Symposium on Deep Mixing and Admixture Stabilization, CD-ROM, Vol. 7, pp.49-52 (2009).

7) M. Kondoh, H. Miyatake, "Development on the Hybrid Application of Deep Mixing Columns Combined with Walls", Proceedings of the Japanese Geotechnical Society Symposium, CD-ROM, Vol. 59, pp.651-658 (2014).

8) S. Tsukuni, "A DETAILED STUDY FOR THE HYBRID APPLICATION OF DEEP MIXING COLUMNS COMBINED WITH WALLS BASED ON THREE DIMENSIONAL FEM ANALYSIS", Journal of the Japan Society of Civil Engineers, Vol. 70, No. 3, pp. 313-327 (2014). 